\title{
40. Dördüncü sınıf öğrencilerinin İngilizce algılarının matematik ve Türkçe başarılarına göre incelenmesi
}

Birol SÜMEN ${ }^{1}$

\section{Özlem ÖZÇAKIR SÜMEN²}

\begin{abstract}
APA: Sümen, B.; Özçakır Sümen, Ö. (2021). Dördüncü sınıf öğrencilerinin İngilizce algılarının matematik ve Türkçe başarılarına göre incelenmesi. RumeliDE Dil ve Edebiyat Araştırmaları Dergisi, (24), 706-717. DOI: 10.29000/rumelide.990178.
\end{abstract}

\section{$\ddot{\mathbf{O z}}$}

İngilizce günümüzde sınırlar ötesinde kullanılan ortak dildir ve birçok ülke okullarda öğrencilere ikinci dil olarak İngilizce öğretmektedir. Bu nedenle öğrencilerin İngilizce başarıları gelecek hayatları açısından önemlidir. Bu çalışmada dördüncü sınıf öğrencilerinin İngilizce algıları matematik ve Türkçe başarıları açısından incelenmiştir. Nitel araştırma yöntemlerinden fenomenoloji deseninde gerçekleştirilen araştırmaya 42 dördüncü sınıf öğrencisi katılmıştır. Araştırmanın verileri zihin haritaları ve yarı yapılandırılmış görüşmelerle toplanmıştır. Zihin haritalarının analiz sonuçları öğrencilerin İngilizce algılarının okul, Dünya dili, duyuşsal özellikler ve sosyal hayat temalarında toplandığını göstermiştir. Ayrıca analiz sonucunda okul temasında ortaya çıkan kodlar; İngilizce kelimeler, İngilizce dersi öğretmeni, ödev, kelime ezberleme, yoğun ders saati, sınav-test, online ders, İngilizce kitapları-sözlük, oyun, çeviri ve telaffuz şeklinde belirlenmiştir. Dünya dili teması yabancı dil öğrenme, yurtdışı-yabancı ülke, turist, yabancı dil konuşabilme, ünlü kişiler, ünlü yerler, alfabe ve yaygın dil kodlarından; duyuşsal özellikler teması zor-sıkıcı, gerekli, sevmeme, annem, sevgi, heyecan-heves ve sorumluluk kodlarından oluşmuştur. Sosyal hayat temasında ise teknoloji, İngilizce şarkı, yeni kültür, iş hayatı ve alışveriş-ticaret kodları yer almıştır. Öğrencilerin İngilizce algıları matematik ve Türkçe başarıları açısından incelendiğinde; matematik ve Türkçe başarı düzeyleri düşük olan öğrencilerin İngilizce'yi daha çoğunlukla yaşam temasıyla ilişkilendirirken her iki derste de yüksek başarı gösteren öğrencilerin İngilizce’yi en çok okul temasıyla ilişkilendirdiği görülmüştür. Araştırma sonuçları ilgili çalışmalar ışığında tartışılmıştır.

Anahtar kelimeler: Dördüncü sınıf öğrencileri, İngilizce algısı, matematik başarısı, Türkçe başarısı

\section{Examination of fourth-grade students' English perceptions according to their mathematics and Turkish achievement}

\begin{abstract}
English is the lingua franca used across borders today, and many countries teach English as a second language to students in schools. For this reason, students' English achievement is important for their future lives. In this study, fourth-grade students' perceptions of English were examined in terms of their achievement in mathematics and Turkish. 42 fourth-grade students participated in the research, which was carried out in the phenomenology design, one of the qualitative research methods. The data of the research were collected through mind maps and semi-structured interviews. As a result of
\end{abstract}

İngilizce Öğretmeni, MEB (Samsun, Türkiye), birolsumen@gmail.com, ORCID ID: oooo-0oo3-0678-7898 [Araştırma makalesi, Makale kayit tarihi: 16.07.2021-kabul tarihi: 20.09.2021; DOI: 10.29000/rumelide.990178] Dr. Öğr. Üyesi, Ondokuz Mayıs Üniversitesi, Eğitim Fakültesi, Temel Eğitim Bölümü (Samsun, Türkiye), ozlem.ozcakir@omu.edu.tr, ORCID ID: 0000-0002-5140-4510

Adres | Address

RumeliDE Dil ve Edebiyat Araştırmaları Dergisi Osmanağa Mahallesi, Mürver Çiçeği Sokak, No:14/8 Kadıköy - İSTANBUL / TÜRKIYE 34714 e-posta: editor@rumelide.com

RumeliDE Journal of Language and Literature Studies

Osmanağa Mahallesi, Mürver Çiçeği Sokak, No:14/8

Kadıköy - ISTANBUL / TURKEY 34714

e-mail: editor@rumelide.com,

tel: +90 505 7958124, +90 2167730616 phone: +90 505 7958124, +90 2167730616 


\begin{abstract}
the research, the analysis results of the mind maps showed that the students' English perceptions were gathered under the themes of school, world language, affective characteristics and social life. As a result of the analysis, the codes that emerged in the school theme were determined as English words, English lesson teacher, homework, word memorization, intensive lesson hours, examination-test, online course, English books-dictionary, game, translation and pronunciation. World language theme consisted of learning a foreign language, abroad-foreign country, tourist, speaking a foreign language, famous people, famous places, alphabet and common language codes; affective characteristics theme consisted of difficult-boring, necessary, dislike, mother, love, excitemententhusiasm and responsibility codes. Social life theme included the codes of technology, English song, new culture, business life and shopping-trade codes. When students' perceptions of English were examined in terms of mathematics and Turkish achievement; it has been found that students with low achievement levels in mathematics and Turkish mostly associate English with the theme of life, while students with high achievement in both courses mostly associate English with the theme of school. The results of the research were discussed in the light of related studies.
\end{abstract}

Keywords: English perception, fourth-grade students, mathematics achievement, Turkish achievement

\title{
Giriş
}

İngilizce yeterliliği bireylere ekonomik, sosyal ve eğitim alanlarında firsatlar sağlar; kişisel refahın artırılabilmesi için maddi kaynaklara ulaşım imkanı sunar (Bourdieu, 1991). İngilizce yurtiçi veya yurtdışında yüksek öğrenim, kamu veya özel sektörde istihdam, mesleki ilerleme ve sosyal prestij için bir pasaport niteliğindedir (Hu, 2002, 2003; Jiang, 2003). Başarılı kalkınma performansı sergileyen Brezilya, Rusya, Hindistan ve Çin gibi BRICS (Brezilya, Rusya, Hindistan, Çin ve Güney Afrika Cumhuriyeti) ülkelerinin yüksek nüfus ve demografik problemlerine rağmen endeks puanlarının Türkiye'den yüksek olduğu ve bu ülkelerin İngilizce eğitimini kalkınma stratejilerinin bir parçası olarak gördükleri bilinmektedir (Koru ve Akesson, 2011). Bu nedenle İngilizce’ye verilen önem ve İngilizce yeterliliğine yönelik artan talepler nedeniyle, İngilizce eğitimine büyük çaba harcanmakta ve büyük kaynaklar yatırılmaktadır (Hu, 2003; Nunan, 2003). Ülkemizde İngilizce eğitimine başlama yaşı 20122013 eğitim yllından itibaren 4+4+4 eğitim sistemine geçilmesiyle birlikte ilkokul 2. sınıf düzeyine düşürülmüştür. Ancak ülkemizde verilen İngilizce eğitimi konusundaki tartışmalar halen sürmektedir (Can ve Can, 2014; Çelebi, 2006; Yaman, 2018). Öğrencilerin İngilizce başarısında İngilizce'yi nasıl algıladıkları önemli rol oynar. Bu nedenle bu araştırmada dördüncü sınıf öğrencilerinin İngilizce algıları matematik ve Türkçe başarıları açısından incelenmiştir.

\section{Ülkemizde yabancı dil eğitimi}

Ülkemizde yabancı dil eğitiminde önceleri Fransızca'ya ağırlık verilirken, zamanla dünya genelindeki değişim ve küreselleşme ile birlikte İngilizce'ye öncelik verilmeye başlanmıştır (Demirpolat, 2005). Dil eğitimi açısından 1997 yılında uygulamaya konulan Sekiz Yıllık Eğitim Reformu ile yeni bir döneme geçilmiş ancak İngilizce eğitimi geleneksel yaklaşımlarla verilmeye devam edilmiştir (Haznedar, 2004; Kırkgöz, 2007). Bu dönemde ortaöğretim düzeyinde başlayan İngilizce derslerinin 4. sinfftan itibaren verilmeye başlanması ve İngilizce eğitimi açısından 'erken yaş' ilkesinin benimsenmesi İngilizce eğitimi açısından önemli kazanımlardır (Yaman, 2018). Ülkemizde yabancı dil eğitimi anlayışının değişımi ise 2006 yılında uygulamaya konulan yeni öğretim programıyla sağlanmış; İngilizce 4. sınıftan itibaren bütüncül ve iletişim odaklı bir yaklaşımla öğretilmeye başlanmıştır (Haznedar, 2010). 2012-2013

\footnotetext{
Adres $\mid$ Address

RumeliDE Dil ve Edebiyat Araştırmalar Dergisi $\quad$ RumeliDE Journal of Language and Literature Studies Osmanağa Mahallesi, Mürver Çiçeği Sokak, No:14/8 Osmanağa Mahallesi, Mürver Çiçeği Sokak, No:14/8 Kadıköy - İSTANBUL / TÜRKIYE 34714 Kadıköy - ISTANBUL / TURKEY 34714 e-posta: editor@rumelide.com e-mail: editor@rumelide.com, tel: +90 505 7958124, +90 2167730616 phone: +90 505 7958124, +90 2167730616
} 
Examination of fourth-grade students' English perceptions according to their mathematics and Turkish achievement / B. Sümen; Ö. Özçakır Sümen (pp. 706-717)

yılından itibaren dil eğitimi yaşı daha aşağı çekilerek, İngilizce dersi öğrencilere 2. sınıftan itibaren verilmeye başlanmıştır.

İngilizce öğretim programında, programın “İngilizce öğrenmeye yeni başlayan çocukların yabancı dil öğrenmeyi sevmeleri ve bir yabancı dili öğrenirken kendilerine güvenerek dil öğreniminin zevkli bir süreç olduğunu benimsemeleri” gereksinimi üzerine kurulduğu ve programın esas hedefinin 2. sınıf öğrencilerinde yabancı dil öğrenme sevgisini oluşturmak olduğu belirtilmektedir (Milli Eğitim Bakanlığı [MEB], 2018, s. 16). Programda İngilizce eğitimi 2. sınıf düzeyinde 2 saatle başlamakta, sınıf düzeyi arttıkça ders saati de giderek artmaktadır. Tablo 1, ilkokul ve ortaokul düzeyinde uygulanan haftalık Türkçe, matematik ve İngilizce ders saati sayılarını göstermektedir.

Tablo 1. İlkokul ve ortaokullarda uygulanan Türkçe, Matematik ve İngilizce derslerine ait haftalık ders saati sayıları (MEB, 2017'den uyarlanmıştır)

\begin{tabular}{lllllllll}
\hline & \multicolumn{7}{l}{ Siniflar } & \multicolumn{7}{c}{ Ortaokul } \\
\cline { 2 - 9 } & İlkokul & 2 & 3 & 4 & 5 & 6 & 7 & 8 \\
\cline { 2 - 9 } & 1 & 8 & 8 & 6 & 6 & 5 & 5 \\
\hline Türkçe & 10 & 10 & 5 & 5 & 5 & 5 & 5 & 5 \\
\hline İngilizce & - & 2 & 2 & 2 & 3 & 3 & 4 & 4 \\
\hline
\end{tabular}

Tablo 1'de haftalık İngilizce ders saati sayılarının Türkçe ve matematik derslerine göre daha az olduğu ancak sınıf düzeyi ilerledikçe arttı̆̆ görülmektedir. Öğrencilerin İngilizce derslerindeki başarısında haftalık gördükleri ders sayısı önemli bir etkendir. Özellikle Dünya’nın gelişmiş ekonomilerinden biri olan Çin'de ilkokul düzeyinde haftalık İngilizce ders saati sayısının 3 saat olduğu ve ülkemizdeki İngilizce ders saati sayısı ile benzeştiği görülmektedir (Qi, 2016).

Öğrencilerin İngilizce başarısında İngilizce dersini nasıl algıladıkları önemlidir. Bu konuda yapılan çalışmalar ilkokul öğrencilerinin İngilizce eğitimine ve İngilizce’nin erken yaşta öğretilmesine olumlu baktıklarını, derse yönelik tutumlarının olumlu olduğunu ortaya koymuştur (Kızltan ve Atlı, 2013; Qi, 2016). Öte yandan ortaokul, lise ve üniversite öğrencilerinin İngilizce’ye karşı olumlu (Kanat ve Kozikoğlu, 2018; Siregar, Saragih ve Husein, 2018; Rukh, 2014; Tran ve Duong, 2013) ve olumsuz tutum (Abidin, Pour-Mohammadi ve Alzwari, 2012; Munir ve Rehman, 2015) gösterdikleri de bu alanda yapılan çalışmaların sonuçları arasındadır. Teknolojik yöntemlerle yapılan dil eğitimi (Ahmad ve Yamat, 2020) ve dijital İngilizce öğrenme aktiviteleri de (Lee, 2020) öğrencilerin İngilizce algısını olumlu yönde etkilemektedir. Ayrıca, çalışmalar duyuşsal özelliklerin akademik başarı üzerinde etkili olduğunu ve akademik başarıdaki değişkenliği açıkladığını göstermektedir (Hemmings, Grootenboer ve Kay, 2011; Hortwitz, 2001; Senemoğlu, 2009; Wigfield ve Wentzel, 2007). Nitekim, İngilizce dersine yönelik tutum ile akademik başarı ve İngilizce başarısı ile Türkçe başarısı arasında anlamlı ilişkiler olduğu belirlenmiştir (Kazazoğlu, 2013). Bu açıdan öğrencilerin matematik ve Türkçe başarılarının İngilizce algılarını nasıl etkilediği önemli bir konudur, ancak bu yönde yapılmış bir çalışma bulunmamaktadır. Bu konu ile ilişkili farklı bir çalışmada, Sandilos, Baroody, Rimm-Kaufman ve Merritt (2020) öğrencilerin İngilizce yeterlilikleri ile matematik ve fen başarıları arasındaki ilişkileri regresyon analizi ile incelemiştir. Araştırma sonucunda, düşük İngilizce yeterliliğine sahip öğrencilerin İngilizcesi daha iyi olan akranlarına göre matematik ve fende daha düşük başarı ve öz-yeterlik gösterdikleri bulunmuştur. Ayrıca, öğrencilerin öz-yeterlik düzeylerinin düşük İngilizce yeterlilik düzeyi ile fen başarısı arasındaki ilişkiyi kısmen açıklarken, matematik için açıklamadığı görülmüştür. Ancak

\begin{tabular}{r|l} 
Adres & Address \\
RumeliDE Dil ve Edebiyat Araştırmaları Dergisi & RumeliDE Journal of Language and Literature Studies \\
Osmanağa Mahallesi, Mürver Çiçeği Sokak, No:14/8 & Osmanağa Mahallesi, Mürver Çiçeği Sokak, No:14/8 \\
Kadıköy - İSTANBUL / TÜRKIYY 34714 & Kadıköy - ISTANBUL / TURKEY 34714 \\
e-posta: editor@rumelide.com & e-mail: editor@ rumelide.com, \\
tel: +90 505 7958124, +90 2167730616 & phone: +90 505 7958124, +90 2167730616
\end{tabular}


alanyazında öğrencilerin İngilizce algılarını zihin haritaları ile inceleyen çalışmaya rastlanmamıştır. Bu çalışma özellikle öğrencilerin İngilizce algılarını zihin haritaları ile incelemeyi ve İngilizce algılarının matematik ve Türkçe başarılarına göre nasıl değiştiğini belirlemeyi amaçlamaktadır. Öğrencilerin İngilizce algılarının bu iki temel alandaki başarı düzeylerine göre nasıl şekillendiğinin belirlenmesi İngilizce başarıları açısından önemlidir. $\mathrm{Bu}$ yönüyle çalışmanın alana katkı sağlayacağı düşünülmektedir.

\section{Çalışmanın amacı}

Bu çalışmada öğrencilerin İngilizce dersine yönelik algıları ve bu algılarının matematik ve Türkçe başarılarına göre nasıl değiştiği incelenmiştir. Araştırmada şu sorulara cevap aranmaktadır:

1. Dördüncü sınıf öğrencilerinin zihin haritalarında ifade ettikleri İngilizce algıları

a) hangi kod ve temalarda toplanmaktadır?

b) matematik ve Türkçe başarı düzeylerine göre hangi temalarda toplanmaktadır?

2. Öğrencilerin İngilizce dersine yönelik düşünceleri nelerdir?

\section{Yöntem}

İlkokul dördüncü sınıf öğrencilerinin İngilizce dersine yönelik algılarını inceleyen bu araştırmada nitel araştırma yöntemlerinden fenomenoloji deseni kullanılmıştır. Fenomenoloji günlük deneyimlerin anlamı ve doğası hakkında derinlemesine bir anlayış edinilmesini amaçlayan bir yöntemdir (Patton, 2002). Bu kapsamda çalışmada belirlenen fenomen öğrencilerin İngilizce algılarıdır.

\section{Katılımcılar}

Bu çalışma 2020-2021 eğitim yılı bahar döneminde bir devlet okulunda gerçekleştirilmiştir. Çalışmanın katılımcıları kolay ulaşılabilir örneklem örneklemle seçilmiştir. Pandemi nedeniyle okul devam eden öğrenci sayısı sınırlı olduğu için çalışmanın uygulandığı gün okulda bulunan tüm öğrencilerden gönüllü olan 42 öğrenci çalışmaya katılmıştır. Katılımcıların 18'i kız ve 24’ü erkek öğrencidir.

\section{Veri toplama araçları}

Araştırmanın verileri zihin haritaları ve yarı yapılandırılmış görüşme formu ile toplanmıştır. Öğrencilerin Türkçe ve matematik başarı düzeyleri ise bu derslere ait karne notları ve öğretmenin görüşleri dikkate alınarak belirlenmiştir.

Zihin haritası: Öğrencilerin İngilizce algıları "İngilizce” temasına yönelik çizdikleri zihin haritaları ile belirlenmiştir. Zihin haritası beynin potansiyelini açığa çıkaran güçlü bir tekniktir. İlk defa Tony BUZAN tarafından bir not alma tekniği olarak geliştirilmiştir (Brinkmann, 2003). Buzan (1996) zihin haritasını merkezdeki bir ana temadan etrafa yayılan dallar aracılığıyla temanın kavramlarla ilişkilerinin kurulduğu bir yapı olarak nitelendirmektedir. Zihin haritasının yapısı bir ağaca benzemekte, ağacın gövdesinde zihin haritasının konusu yer alırken konuya fikirleri bağlamak için çizilen çizgiler, ağacın dalları gibi yayılmaktadır (Brinkmann, 2003). Zihin haritası çizerken öğrencilere merkezdeki ana tema

\footnotetext{
\begin{tabular}{r|l} 
Adres & Address \\
RumeliDE Dil ve Edebiyat Araştırmalar Dergisi & RumeliDE Journal of Language and Literature Studies
\end{tabular}

Osmanağa Mahallesi, Mürver Çiçeği Sokak, No:14/8 $\quad$ Osmanağa Mahallesi, Mürver Çiçeği Sokak, No:14/8

Kadıköy - İSTANBUL / TÜRKIYE 34714 Kadıköy - ISTANBUL / TURKEY 34714

e-posta: editor@rumelide.com e-mail: editor@rumelide.com,

tel: +90 505 7958124, +90 2167730616 phone: +90 505 7958124, +90 2167730616
} 
Examination of fourth-grade students' English perceptions according to their mathematics and Turkish achievement / B. Sümen; Ö. Özçakır Sümen (pp. 706-717)

İngilizce olarak verilmiş ve İngilizce kelimesinin zihinlerinde çağrıştırdığı kavramları içeren bir zihin haritası çizmeleri istenmiştir.

Yarı yapılandırılmış görüşme formu: Öğrencilerin İngilizce'ye ve İngilizce dersine yönelik düşüncelerini belirlemek amacıyla yarı yapılandırılmış görüşme soruları hazırlanmıştır. Sorularda öğrencilerden zihin haritalarında çizdikleri kavramları ve İngilizce dersine yönelik düşüncelerini açıklamaları istenmiştir. Görüşme soruları uzman görüşüne sunularak öğrencilerin seviyesine göre düzenlenmiş ve çalışmada uygulanmıştır. Görüşme formunda yer alan sorulardan bir örnek şu şekildedir:

“İngilizce öğrenmek istiyor musun? Sence İngilizce öğrenmek gerekli mi? Neden? İşine yarayacağın düşünüyor musun? Hangi alanlarda işine yarayabilir?”

\section{Verilerin toplanması}

Araştırmada veri toplama araçları uygulanmadan önce öğrencilere çalışmanın amacı ve kapsamı açıklanmıştır. Daha sonra çalışmaya katılmak için gönüllü olan öğrencilere zihin haritası çizmeleri için boş kağıtlar dağıtılmıştır. Öğrencilere örnek bir zihin haritası gösterilerek üzerinde zihin haritasının ne olduğu ve nasıl çizileceği anlatılmıştır. Öğrencilerden zihin haritalarında merkeze İngilizce yazmaları ve İngilizce/İngilizce dersi ile ilgili akıllarına gelen herşeyi zihin haritalarında ifade etmeleri istenmiştir. Zihin haritası çizimi için öğrencilere bir ders saati süre verilmiştir. Bu sürede öğrencilerin anlamadıkları noktalar açıklanmış, sordukları sorular cevaplanmıştır. Zihin haritası çizimi bittikten sonra öğrencilere yarı yapılandırılmış görüşme formları dağıtılmış ve formda yazan soruları yazılı olarak cevaplamaları istenmiştir.

\section{Veri analizi}

Zihin haritalarının analizinde Creswell (2007)'in önerdiği veri analizi adımları izlenmiştir. Bu adımlar veriyi analiz için hazırlama ve düzenleme, veriyi kodlayarak temalara indirgeme ve yoğunlaştırma, son olarak verilerin şekiller veya tablolarla ifade edilmesidir. Bu kapsamda öğrencilerin çizdiği zihin haritaları sıralanarak öğrencilerin cinsiyetleri, matematik ve Türkçe başarı düzeyleri dikkate alınarak kodlanmıştır. Öğrenciler matematik ve Türkçe başarı düzeylerine göre düşük (d), orta (o) ve yüksek (y) olmak üzere üç düzeyde sınıflanmıştır. Örneğin, K1ToMy şeklinde kodlanan bir öğrenci orta düzeyde Türkçe başarısına, yüksek düzeyde matematik başarısına sahip 1 numaralı kız öğrenciyi göstermektedir. Daha sonra zihin haritaları içerik analizi ile analiz edilerek haritalarda ifade edilen kavramlar kodlanmıştır. Kodlama işlemi bittikten sonra yapılan kodlar tekrar incelenerek benzer kodlar biraraya getirilmiş ve temalar oluşturulmuştur. Üçüncü aşamada elde edilen kod ve temaları içeren tablolar çizilmiş, kod ve temalara ait frekans sayıları hesaplanmıştır.

Öğrencilerin görüşme sorularına verdikleri yanıtlar ise betimsel olarak analiz edilmiştir. Bu amaçla öncelikle öğrencilerin yanıtları sırayla okunarak içerdikleri temel noktalar belirlenmiştir. Daha sonra tüm öğrencilerin yanıtları bu temel noktalar çerçevesinde betimsel olarak özetlenmiştir. Ayrıca öğrenci görüşlerinden direk alıntılarla desteklenmiştir. Veri analizinin güvenirliğini sağlamak amacıyla zihin haritaları araştırmacılar tarafından ayrı ayrı kodlanarak aralarındaki tutarlılık Miles ve Huberman (1994) içsel tutarlılık formülü (Güvenirlik katsayısını= görüş birliği/görüş birliği + görüş ayrılı̆̆ı) kullanılarak hesaplanmıştır. \% 84 olarak hesaplanan tutarlılık katsayısının yeterli olduğu görülmüştür.

\footnotetext{
Adres | Address

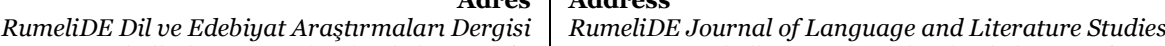
Osmanağa Mahallesi, Mürver Çiçeği Sokak, No:14/8 Osmanağa Mahallesi, Mürver Çiçeği Sokak, No:14/8 Kadıköy - İSTANBUL / TÜRKIYE 34714 Kadıköy - ISTANBUL / TURKEY 34714 e-posta: editor@rumelide.com e-mail: editor@rumelide.com, tel: +90 505 7958124, +90 2167730616 phone: +90 505 7958124, +90 2167730616
} 


\section{Etik kurul onayı}

$\mathrm{Bu}$ çalışmanın uygulanması sürecinde etik kurallara uyulmuş, veriler gönüllülük esasına göre toplanmıştır. Araştırmanın etik kurul onayı Ondokuz Mayıs Üniversitesi Sosyal ve Beşeri Bilimler Etik Kurulu'nun 2021/251 sayılı kararı ile alınmıştır.

\section{Bulgular}

\section{Öğrencilerin İngilizce algılarına yönelik bulgular}

Öğrencilerin zihin haritaları analiz edildiğinde İngilizce algılarının Tablo 2'de ifade edilen kod ve temalarda toplandığı belirlenmiştir.

Tablo 2. Zihin haritalarının analizi sonucu elde edilen kod ve temalar

\begin{tabular}{|c|c|c|c|c|}
\hline Temalar & Kodlar & \multicolumn{2}{|l|}{ Öğrenciler } & $\mathbf{f}$ \\
\hline \multirow[t]{11}{*}{ Okul } & $\begin{array}{l}\text { İngilizce } \\
\text { kelimeler }\end{array}$ & \multicolumn{2}{|c|}{$\begin{array}{l}\text { K1ToMy, K2TyMy, E4TyMy, K5TyMy, E6TyMy, E7TyMy, E8TyMy, } \\
\text { E12TyMy, K13ToMo, E16TyMy, E17ToMo, K19TyMy, E21TyMy, } \\
\text { E22TdMd, K23TyMy, K24TyMy, E27ToMo, E28ToMd, E3oTdMd, } \\
\text { E42TyMy }\end{array}$} & 20 \\
\hline & $\begin{array}{l}\text { İngilizce dersi } \\
\text { öğretmeni }\end{array}$ & \multicolumn{2}{|c|}{$\begin{array}{l}\text { K1ToMy, K2TyMy, K3TdMy, E4TyMy, K5TyMy, E6TyMy, E7TyMy, } \\
\text { E8TyMy, E9ToMy, K10TyMy, E11TyMy, E12TyMy, K13ToMo, } \\
\text { E17ToMo, K19TyMy, K23TyMy }\end{array}$} & 16 \\
\hline & Ödev & \multicolumn{2}{|c|}{$\begin{array}{l}\text { K1ToMy, E4TyMy, K5TyMy, E6TyMy, E7TyMy, E8TyMy, E9ToMy, } \\
\text { K13ToMo, K15TyMy, E17ToMo, K29ToMd, E38TdMd, K40TyMo, } \\
\text { E41TdMd, E42TyMy }\end{array}$} & 15 \\
\hline & $\begin{array}{l}\text { Kelime } \\
\text { ezberleme }\end{array}$ & \multicolumn{2}{|c|}{$\begin{array}{l}\text { K1ToMy, K2TyMy, E4TyMy, K5TyMy, E6TyMy, E7TyMy, E8TyMy, } \\
\text { E9ToMy, K10TyMy, E11TyMy, E12TyMy, K13ToMo, E42TyMy }\end{array}$} & 13 \\
\hline & Yoğun ders saati & \multicolumn{2}{|c|}{ K2ТyMy, E6TyMy, E8TyMy, E9ToMy, K10ТyMy, E11ТyMy, E12ТyМy } & 7 \\
\hline & Sinav-test & \multicolumn{2}{|c|}{ 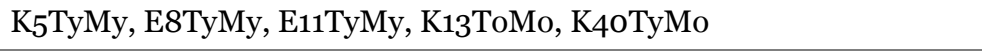 } & 5 \\
\hline & Online ders & \multicolumn{2}{|c|}{ K3TdMy, E4TyMy, E6TyMy, E8TyMy, K13ТoMо } & 5 \\
\hline & $\begin{array}{l}\text { İngilizce } \\
\text { kitapları-sözlük }\end{array}$ & \multicolumn{2}{|c|}{ K2TyMy, E7ТyМy, K13ТoMo, К23ТyМy } & 4 \\
\hline & Oyun & \multicolumn{2}{|c|}{ K5TyМy, E9ToМy,К32ТoMo, K40TyМо } & 4 \\
\hline & Çeviri & \multicolumn{2}{|c|}{ K2TyMy, E7TyMy, K10TyMy } & 3 \\
\hline & Telaffuz & \multicolumn{2}{|l|}{ E7TyMy } & 1 \\
\hline Toplam & 11 & & & 93 \\
\hline \multirow[t]{7}{*}{ Dünya dili } & $\begin{array}{l}\text { Yabancı dil } \\
\text { öğrenme }\end{array}$ & \multicolumn{2}{|c|}{$\begin{array}{l}\text { K2TyMy, K3TdMy, K5TyMy, E7TyMy, E8TyMy, K14TyMo, K15TyMy, } \\
\text { E21TyMy, K24TyMy, E3oTdMd, K32ToMo,E33ToMo, E34TdMo, } \\
\text { E37TdMd, E38TdMd }\end{array}$} & 15 \\
\hline & $\begin{array}{l}\text { Yurtdışı-yabancı } \\
\text { ülke }\end{array}$ & \multicolumn{2}{|c|}{$\begin{array}{l}\text { K2TyMy, K3TdMy, E4TyMy, K5TyMy, E6TyMy, K10TyMy, E11TyMy, } \\
\text { E12TyMy, K14TyMo, K24TyMy, K25TyMy, K29ToMd, E36TdMd, } \\
\text { E38TdMd }\end{array}$} & 14 \\
\hline & Turist & \multicolumn{2}{|c|}{$\begin{array}{l}\text { K2TyMy, K3TdMy, E8TyMy, K10TyMy, K14TyMo, E16TyMy, } \\
\text { E21TyMy, E35ToMd, E37TdMd, E41TdMd }\end{array}$} & 10 \\
\hline & $\begin{array}{l}\text { Yabancı dil } \\
\text { konuşabilme }\end{array}$ & \multicolumn{2}{|c|}{ E21TyMy, K24TyMy, E26TdMd, K32ToMo, E35ToMd, K40TyMo } & 6 \\
\hline & Ünlü kişiler & \multicolumn{2}{|c|}{ E4TyMy, E6TyMy, K14ТyMo, К24ТyМy, К25ТyМy } & 5 \\
\hline & Ünlü yerler & \multicolumn{2}{|l|}{ K24ТyМy, К25ТyМy } & 2 \\
\hline & $\begin{array}{r}\text { RumeliDE Dil ve Edeb } \\
\text { Osmanağa Mahallesi, Mi } \\
\text { Kadıköy - İS } \\
\text { e-po } \\
\text { tel: }+905057\end{array}$ & $\begin{array}{r}\text { Adres } \\
\text { at Arassttrmaları Dergisi } \\
\text { er Ciçeği Sokak, No:14/8 } \\
\text { NBUL / TÜRKIYY } 34714 \\
\text { a: editor@rumelide.com } \\
88124,+90 \text { 216 } 773 \text { o } 616\end{array}$ & $\begin{array}{l}\text { Address } \\
\text { RumeliDE Journal of Language and Literature Studies } \\
\text { Osmanağa Mahallesi, Mürver Ciçeği Sokak, No:14/8 } \\
\text { Kadıköy - ISTANBUL / TURKEY } 34714 \\
\text { e-mail: editor@rumelide.com, } \\
\text { phone: +90 505 7958124, +90 } 216773 \text { o } 616\end{array}$ & \\
\hline
\end{tabular}


Examination of fourth-grade students' English perceptions according to their mathematics and Turkish achievement / B. Sümen; Ö. Özçakır Sümen (pp. 706-717)

\begin{tabular}{|c|c|c|c|}
\hline & Alfabe & E26TdMd, E38TdMd & 2 \\
\hline & Yaygin dil & K14TyMo & 1 \\
\hline Toplam & 8 & & 55 \\
\hline \multirow{7}{*}{$\begin{array}{c}\text { Duyuşsal } \\
\text { özellikler }\end{array}$} & Zor-sıkıcı & E7TyMy,K18TyMy, K20TyMy, E22TdMd, E41TdMd, E42TyMy & 6 \\
\hline & Gerekli & E22TdMd, E27ToMo, K31ToMo, E34TdMo, E39TdMd, E41TdMd & 6 \\
\hline & Sevmeme & K18TyMy, E22TdMd & 2 \\
\hline & Annem & K2TyMy, E6TyMy & 2 \\
\hline & Sevgi & K5TyMy & 1 \\
\hline & Heyecan-heves & E42TyMy & 1 \\
\hline & Sorumluluk & E7TyMy & 1 \\
\hline Toplam & 7 & & 19 \\
\hline \multirow{5}{*}{$\begin{array}{l}\text { Sosyal } \\
\text { hayat }\end{array}$} & Teknoloji & E6TyMy, K10TyMy, K23TyMy, K4оTyMо & 4 \\
\hline & İngilizce şarkı & K23ТyMy, K24ТyMy, K40TyMо & 3 \\
\hline & Yeni kültür & E6TyMy, K14TyMo, K15ТyМy & 3 \\
\hline & Iş hayatı & K31ToMo, E39TdMd & 2 \\
\hline & Alışveriş-ticaret & E36TdMd, E39TdMd & 2 \\
\hline Toplam & 5 & & 14 \\
\hline
\end{tabular}

Tablo 2'de görüldüğü üzere, analiz sonuçları öğrencilerin İngilizce algılarının okul, Dünya dili, duyuşsal özellikler ve sosyal hayat temalarında toplandığını göstermiştir. Bununla birlikte okul temasında 11 kod ortaya çıkmıştır. Bunlar İngilizce kelimeler, İngilizce dersi öğretmeni, ödev, kelime ezberleme, yoğun ders saati, sınav-test, online ders, İngilizce kitapları-sözlük, oyun, çeviri ve telaffuzdur. Dünya dili teması yabancı dil öğrenme, yurtdışı-yabancı ülke, turist, yabancı dil konuşabilme, ünlü kişiler, ünlü yerler, alfabe ve yaygın dil olmak üzere 8 kod; duyuşsal özellikler teması zor-sıkıcı, gerekli, sevmeme, annem, sevgi, heyecan-heves ve sorumluluk olmak üzere toplam 7 kod içermektedir. Sosyal hayat temasında ise teknoloji, İngilizce şarkı, yeni kültür, iş hayatı ve alışveriş-ticaretten oluşan 5 farklı kod yer almıştır.

Öğrencilerin zihin haritalarının analizi sonucu elde edilen temalar matematik ve Türkçe başarı düzeylerine göre analiz edildiğinde Tablo 3’teki sonuçlara ulaşılmıştır.

Tablo 3. Temaların matematik ve Türkçe başarı düzeylerine göre karşılaştırılması

\begin{tabular}{|c|c|c|c|c|c|c|c|c|}
\hline & \multirow[t]{2}{*}{ Öğrenciler } & \multicolumn{3}{|c|}{ Matematik (f) } & \multicolumn{3}{|c|}{ Türkçe (f) } & \multirow[t]{2}{*}{$\mathbf{f}$} \\
\hline & & 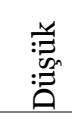 & $\stackrel{\widetilde{\pi}}{0}$ & 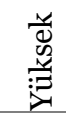 & 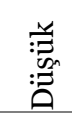 & $\stackrel{\pi}{5}$ & 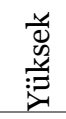 & \\
\hline Okul & $\begin{array}{l}\text { K1ToMy, K2TyMy, K3TdMy, E4TyMy, } \\
\text { K5TyMy, E6TyMy, E7TyMy, E8TyMy, } \\
\text { E9ToMy, K10TyMy, E11TyMy, } \\
\text { E12TyMy, K13ToMo, } \\
\text { K15TyMy,E16TyMy, E17ToMo, } \\
\text { K19TyMy, E21TyMy, E22TdMd, } \\
\text { K23TyMy, K24TyMy, E27ToMo, } \\
\text { E28ToMd, K29ToMd, E3oTdMd, } \\
\text { K32ToMo, E38TdMd,K4oTyMo, } \\
\text { E41TdMd, E42TyMy }\end{array}$ & 6 & 5 & 19 & 5 & 8 & 17 & 30 \\
\hline
\end{tabular}




\begin{tabular}{|c|c|c|c|c|c|c|c|c|}
\hline Yaşam & $\begin{array}{l}\text { K2TyMy, K3TdMy, E4TyMy, K5TyMy, } \\
\text { E6TyMy, E7TyMy, E8TyMy, K10TyMy, } \\
\text { E11TyMy, E12TyMy, K14TyMo, } \\
\text { K15TyMy, E16TyMy,E21TyMy, } \\
\text { K24TyMy, K25TyMy, E26TdMd, } \\
\text { K29ToMd, E30TdMd, } \\
\text { K32ToMo,E33ToMo, E34TdMo, } \\
\text { E35ToMd, E36TdMd,E37TdMd, } \\
\text { E38TdMd, K40TyMo, E41TdMd }\end{array}$ & 8 & 5 & 15 & 8 & 4 & 16 & 28 \\
\hline $\begin{array}{l}\text { Duyuşsal } \\
\text { özellikler }\end{array}$ & $\begin{array}{l}\text { K2TyMy, K5TyMy, E6TyMy, } \\
\text { E7TyMy,K18TyMy, K20TyMy, } \\
\text { E22TdMd, E27ToMo, K31ToMo, } \\
\text { E34TdMo, E39TdMd, E41TdMd, } \\
\text { E42TyMy }\end{array}$ & 3 & 3 & 7 & 4 & 2 & 7 & 13 \\
\hline $\begin{array}{l}\text { Sosyal } \\
\text { hayat }\end{array}$ & $\begin{array}{l}\text { E6TyMy, K10TyMy, K14TyMo, } \\
\text { K15TyMy, K23TyMy, } \\
\text { K24TyMy,K31ToMo, E36TdMd, } \\
\text { E39TdMd, K40TyMo }\end{array}$ & 2 & 3 & 5 & 2 & 1 & 7 & 10 \\
\hline Toplam & & 19 & 16 & 46 & 19 & 15 & 47 & \\
\hline
\end{tabular}

Tablo 3 incelendiğinde, öğrencilerin matematik başarı düzeylerine göre İngilizce algılarının farklı temalarda yoğunlaştığı görülmektedir. Matematik başarı düzeyi düşük olan öğrencilerin İngilizce algıları yaşam temasında ( $\mathrm{f}=8$ ) toplanırken, matematik başarı düzeyi yüksek olan öğrenciler İngilizce'yi daha çok okul teması (f=19) ile ilişkilendirmiştir. Benzer biçimde öğrencilerin İngilizce algıları Türkçe başarı düzeylerine göre de farklılaşmıştır. Türkçe başarısı düşük olan öğrenciler İngilizce'yi çoğunlukla yaşam teması ile $(f=8)$ ilişkilendirirken; orta düzeyde başarı gösterenlerin çoğunluğu $(f=8)$ ve yüksek düzeyde başarı gösterenlerin büyük çoğunluğu $(\mathrm{f}=17)$ İngilizce'yi okul teması ile ilişkilendirmiştir. Şekil 1'de bir öğrenciye (K5TyMy) ait zihin haritası görülmektedir.

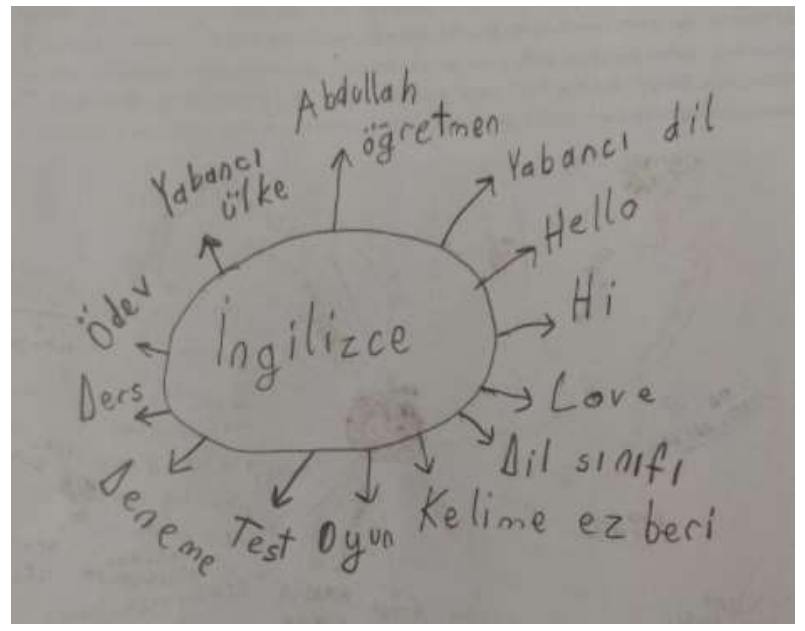

Şekil 1. Bir öğrenciye ait zihin haritası

\section{Öğrencilerin İngilizce dersine yönelik düşüncelerine ilişkin bulgular}

Öğrencilerin görüşme sorularına verdiği yanıtlar incelendiğinde İngilizce dersine yönelik düşüncelerinin İngilizce'yi sevme durumları, İngilizce'nin gerekliliğine ilişkin düşünceleri ve İngilizce derslerinin nasıl işlenmesi gerektiğine yönelik düşünceleri olmak üzere üç başlıkta toplandığı belirlenmiştir. Öğrencilerin büyük çoğunluğu görüşme sorularına verdiği yanıtlarda İngilizce'yi 
Examination of fourth-grade students' English perceptions according to their mathematics and Turkish achievement / B. Sümen; Ö. Özçakır Sümen (pp. 706-717)

sevdiğini ve merak duyduğunu ifade etmiştir. Öğrenciler İngilizce’yi zevkli ve eğlenceli bulduklarını ve gerekli bir ders olarak gördüklerini belirtmişlerdir. Bu konudaki öğrenci görüşlerinden bazı örnekler şu şekildedir: "Evet, seviyorum. Bana eğlenceli geliyor" (E11TyMy). "Seviyorum çünkü başka diller öğrenmek güzel” (K15TyMy). "İngilizce’yi seviyorum çünkü yabancr ülkelere gittiğim zaman İngilizce konuşabileceğim”(E16TyMy).

Öğrenciler çoğunlukla İngilizce’yi yaygın bir dil olduğu için gerekli görmekte, yüksek öğrenimde veya meslek hayatlarında ihtiyaç duyacaklarını düşünmektedir. Bu nedenle İngilizce'yi ileri yaşamları için önemli ve gerekli bir ders olarak nitelendirmişlerdir. İngilizce öğrenmenin yabancılarla iletişim kurma, yabancı ülkeleri gezme açısından faydalı olacağını belirtmişlerdir. Örneğin, bazı öğrencilerin bu konudaki ifadeleri şu şekilde sıralanabilir: "Evet, İngilizce gerekli. Çünkü yabancı bir ülkeye gidersek iletişim kurabiliriz” (K5TyMy). "Evet, çünkü Dünya'da en çok kullanılan dillerden biri. Yurtdışına gitiğimde herkesin bildiği bir dili bilmem iletişimimi kolaylaştırtr” (E7TyMy). “Gerekli bir ders, çünkü geleceğimizde lazım olan bir dil” (E27ToMo).

Öğrencilere İngilizce derslerinin nasıl işlenmesi gerektiği sorulduğunda ise daha çok oyunlarla, eğlenceli hale getirilerek işlenmesi gerektiğini ifade etmişlerdir. Sorulara verilen yantllarda İngilizce derslerinde öğrenilen kelimelerin tekrar edilmesi, farklı etkinlikler yapılması, yarışmalar düzenlenmesi ve test çözülmesi gerektiği vurgulanmıştır. Bu konudaki bazı görüşler şu şekildedir: "[İngilizce] Oyunlarla öğretilirse daha iyi olur" (E12TyMy). "Oyun oynatarak, etkinlik yapttrarak anlatzlabilir. [Ben] Dersi iyi dinleyince daha iyi anlyyorum" (E37TdMd). "Sürekli kitaplardan değil de, biraz oyunlarla ders işlenirse daha eğlenceli ve öğrenilmesi kolay, güzel olur”(К24TyMy).

\section{Tartışma ve sonuç}

Öğrencilerin gelecekteki İngilizce başarıları açısından erken yaşlardaki İngilizce algıları önemlidir. Bu nedenle bu çalışmada dördüncü sınıf öğrencilerinin İngilizce algıları ve bu algılarının matematik ve Türkçe başarılarına göre farklılaşma durumu incelenmiştir. Araştırma sonuçları öğrencilerin İngilizce algılarının okul, Dünya dili, duyuşsal özellikler ve sosyal hayat temalarında toplandığını göstermiştir. Bu temalardan en yüksek frekansa sahip okul teması öğrencilerin İngilizce'yi daha çoğunlukla bir okul dersi olarak gördüklerini ortaya koymuştur. Bunun dışında öğrencilerin İngilizce'yi en fazla bir Dünya dili olarak gördükleri ve önemli bir ders olarak algıladıkları ortaya çıkmıştır. En yüksek frekansa sahip bu iki tema dışında, öğrencilerin İngilizce’ye karşı duygusal durumlarını yansıttıkları duyuşsal özellikler teması ve İngilizce'nin günlük hayata yansımalarını içeren sosyal hayat teması veri analizi sonucu ortaya çıkan sonuçlardır. Bu temalar öğrencilerin zihinlerinde İngilizce'nin dört temel alanda şekillendiğini göstermiştir. Araştırmada, öğrencilerin İngilizce algıları matematik ve Türkçe başarı düzeylerine göre incelenmiş ve sonuçlar öğrencilerin bu iki temel alandaki başarı düzeylerinin İngilizce algılarını etkilediğini göstermiştir. Matematik başarı düzeyi düşük olan öğrenciler İngilizce'yi daha çok yaşamla ilgili bir alan olarak algılarken matematikte yüksek başarı gösteren öğrenciler İngilizce'yi daha çok okul teması ile ilişkilendirmiştir. Benzer biçimde düşük Türkçe başarısına sahip öğrenciler İngilizceyi yaşam temasıyla, yüksek başarılı öğrenciler okul temasıyla ilişkilendirmiştir. Bu durum matematik ve Türkçe derslerine daha çok çalışan yüksek başarılı öğrencilerin bu çalışmalarının sonucu olarak İngilizce'yi okulla ilişkilendirdiğini ve bir okul dersi olarak gördüklerini ortaya koymuştur. Bu sonuç bu alanlarda başarılı öğrencilerin İngilizce’nin asıl öneminin dünya dili olmasından kaynaklandığını kaçırdığı ve İngilizce'ye okul dersi olarak daha dar bir pencereden baktıkları şeklinde yorumlanabilir. Aksine düşük başarılı öğrenciler ise İngilizce’ye okul/ders dışında farklı bir açıdan bakmakta; İngilizce'yi daha çok Dünya dili olarak algılamaktadır. Öğrencilerin matematik ve Türkçe başarılarının İngilizce algılarını

\footnotetext{
Adres | Address

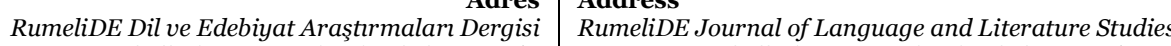
Osmanağa Mahallesi, Mürver Çiçeği Sokak, No:14/8 Osmanağa Mahallesi, Mürver Çiçeği Sokak, No:14/8 Kadıköy - İSTANBUL / TÜRKIYE 34714 Kadıköy - ISTANBUL / TURKEY 34714 e-posta: editor@rumelide.com e-mail: editor@rumelide.com, tel: +90 505 7958124, +90 2167730616 phone: +90 505 7958124, +90 2167730616
} 
etkilemesi önemli bir sonuçtur. Nitekim, literatürde İngilizce başarısı ile Türkçe başarısı arasında anlamlı ilişkiler olduğu (Kazazoğlu, 2013) ve düşük İngilizce yeterliliğgine sahip öğrencilerin matematikte daha düşük başarı gösterdiği bulunmuştur (Sandilos ve diğ., 2020). Bu sonuçlar öğrencilerin matematik, Türkçe ve İngilizce başarıları ile İngilizce algıları arasında ilişkiler olduğunu göstermektedir. Ancak bu konuda daha fazla nicel araştırmaya ve empirik kanıtlara ihtiyaç duyulmaktadır.

Öğrencilerin görüşme sorularına verdiği yanıtlar İngilizce dersini sevdiklerini, eğlenceli bir ders olarak gördüklerini ortaya koymuştur. Bu sonuç, İngilizce öğretmenlerinin dersi eğlenceli hale getirdiğini ve öğrencilere sevdirdiğgini göstermiştir. Çalışmada ulaşlan bu sonuçlar alanyazınla tutarlıdır. Çünkü ilkokul öğrencilerinin İngilizce eğitimine olumlu baktıkları ve tutumlarının olumlu olduğu diğer çalışmaların sonuçlarıyla ortaya koyulmuştur (Kızıltan ve Atll, 2013; Qi, 2016). Ayrıca öğrenciler çoğunlukla İngilizce'yi yaygın bir dil olarak görmekte ve yüksek öğrenimde veya meslek hayatlarında ihtiyaç duyacakları için gerekli olduğunu düşünmektedir. Yabancı ülkeleri gezme, yabancılarla iletişim kurmanın İngilizce öğrenme ile mümkün olduğunu düşünerek İngilizce öğrenmek istediklerini ifade etmişlerdir. Öğrenciler İngilizce derslerinin daha çok oyunlarla işlenmesini, farklı etkinliklerle, yarışmalarla, sınav ve testlerle desteklenmesini istemektedir. Bu sonuçlar öğrencilerin İngilizce'nin hayattaki öneminin farkında olduğunu ve İngilizce öğrenmek istediklerini göstermesi açısından önemlidir. Araştırmanın sonuçları ilkokul düzeyindeki yabancı dil eğitimi açısından önemli bulgular içermektedir.

Araştırma sonucunda öğrencilerin İngilizce’ye yönelik algılarının farklı temalarda toplandığı ve matematik ve Türkçe başarı düzeylerine göre farklılaştığı görülmüştür. Öğrencilerin İngilizce algılarının olumlu olması İngilizce başarıları için önemlidir. İngilizce öğretmenleri İngilizce dersini öğrencilere sevdirmeli, hayatları boyunca ihtiyaç duyacakları önemli bir ders olduğunu hissettirmeli ve İngilizce'ye yönelik olumlu algılara sahip olmalarını sağlamalıdır. Bu alanda farklı sınıf düzeylerinde yapılacak nitel ve nicel çalışmalar alana katkı sağlayacak, İngilizce eğitimine yön verecektir.

\section{Kaynakça}

Abidin, M. J. Z., Pour-Mohammadi, M., \& Alzwari, H. (2012). EFL students' attitudes towards learning English language: The case of Libyan secondary school students. Asian Social Science, 8(2), 119134 .

Ahmad, W. I. W., \& Yamat, H. (2020). Students' perception on learning English language through conventional and digital storytelling. International Journal of Academic Research in Business and Social Sciences, $10(2)$.

Bourdieu, P. (1991). Language and symbolic power. Cambridge, Massachusetts: Harvard University Press.

Buzan, T. (1996). The mind map book. New York: Plume Books.

Brinkmann, A. (2003). Graphical knowledge display - mind mapping and concept mapping as efficient tools in mathematics education. Mathematics Education Review, 16, 35-48.

Can, E. \& Can, C. (2014). Türkiye'de ikinci yabancı dil öğretiminde karşılaşılan sorunlar. Trakya Üniversitesi Eğitim Fakültesi Dergisi, 4(2), 43-63.

Creswell, J. W. (2007). Qualitative inquiry and research design: Choosing among five approaches (second edition). CA: Sage publications.

Çelebi, M. D. (2006). Türkiye'de anadili eğitimi ve yabancı dil öğretimi. Erciyes Üniversitesi Sosyal Bilimler Enstitüsü Dergisi, 1(21), 285-307.

RumeliDE Dil ve Edebiyat Araşttrmaları Dergisi Osmanağa Mahallesi, Mürver Ciçeği Sokak, No:14/8 Kadıköy - ISTANBUL / TÜRKIYE 34714 e-posta: editor@rumelide.com tel: +90 $5057958124,+902167730616$
Address

RumeliDE Journal of Language and Literature Studies

Osmanağa Mahallesi, Mürver Çiçeği Sokak, No:14/8

Kadıköy - ISTANBUL / TURKEY 34714

e-mail: editor@rumelide.com,

phone: +90 505 7958124, +90 2167730616 
Examination of fourth-grade students' English perceptions according to their mathematics and Turkish achievement / B. Sümen; Ö. Özçakır Sümen (pp. 706-717)

Demirpolat, B. C. (2015). Türkiye’nin yabancı dil öğretimiyle imtihanı: sorunlar ve çözüm önerileri. SETA.

Haznedar, B. (2004). Türkiye’de yabancı dil öğretimi: ilköğretim yabancı dil programı. Boğaziçi Üniversitesi Ĕ̆itim Dergisi, 21(2).

Haznedar, B. (2010, November). Türkiye'de yabancı dil eğitimi: Reformlar, yönelimler ve öğretmenlerimiz. İçinde International Conference on New Trends in Education and Their Implications, Antalya, Turkey.

Hemmings, B., Grootenboer, P., \& Kay, R. (2011). Predicting mathematics achievement: The influence of prior achievement and attitudes. International Journal of Science and Mathematics Education, 9(3), 691-705.

Horwitz, E. (2001). Language anxiety and achievement. Annual Review of Applied Linguistics, 21, 112126.

Hu, G. (2002). English language teaching in the People's Republic of China. İçinde Rita Elaine Silver, Guangwei $\mathrm{Hu} \&$ Masakazu Iino (Eds), English language education in China, Japan, and Singapore (s. 1-77). Singapore: National Institute of Education.

Hu, G. (2003). English language teaching in China: Regional differences and contributing factors. Journal of Multilingual and Multicultural Development, 24, 290-318.

Jiang, Y. (2003). English as a Chinese language. English Today, 19(2), 3-8.

Kanat, F., \& Kozikoğlu, İ. (2018). Ortaokul 8. sınıf öğrencilerinin İngilizce öğrenmeye ilişkin özdüzenleme stratejileri, motivasyonel inançları ve tutumları. Erzincan Üniversitesi Eğitim Fakültesi Dergisi, 2O(3), 725-748.

Kazazoğlu, S. (2013). Türkçe ve İngilizce derslerine yönelik tutumun akademik başarıya etkisi. Eğitim ve Bilim, 38(170), 294-307.

Kırkgöz, Y. (2007). English language teaching in Turkey: Policy changes and their implementations. RELC Journal, 38(2), 216-228.

Kızltan, N., \& Atll, I. (2013). Turkish young language learners' attitudes towards English. Hacettepe Üniversitesi Eğitim Fakültesi Dergisi, 28(2), 266-278.

Koru, S., \& Akesson, J. (2011). Türkiye'nin İngilizce açığı. Ankara: Türkiye Ekonomi Politikaları Araştırma Vakfi, 1, 1-19.

Lee, J. S. (2020). Informal digital learning of English and strategic competence for cross-cultural communication: Perception of varieties of English as a mediator. ReCALL, 32(1), 47-62.

Miles, M, B., \& Huberman, A. M. (1994). Qualitative data analysis: An expanded Sourcebook. (2nd ed). Thousand Oaks, CA: Sage.

Milli Eğitim Bakanlı̆̆ı [MEB] (2017). İlköğretim kurumları (ilkokul ve ortaokul) haftahk ders çizelgesi. Ankara. https://ttkb.meb.gov.tr/www/haftalik-ders-cizelgeleri/dosya/ 6 adresinden alınmıştır.

Milli Eğitim Bakanlı̆̆ı [MEB] (2018). İngilizce dersi öğretim programı (İlkokul ve ortaokul 2, 3, 4, 5, 6, 7 ve 8. simuflar). Ankara: MEB Yayınları.

Munir, F., \& Rehman, A. (2015). Attitudes of secondary school students towards English as foreign language: A case study at Lahore, Pakistan. International Journal of Research (IJR), 2(4), 637650. DOI: $10.6084 / \mathrm{mg}$.figshare.4284458.

Nunan, D. (2003). The impact of English as a global language on educational policies and practices in the Asia-Pacific Region. TESOL quarterly, 37(4), 589-613.

Patton, M. Q. (2002). Qualitative research \& evaluation methods (3rd ed.). Thousand Oaks, CA: Sage.

Qi, G. Y. (2016). The importance of English in primary school education in China: perceptions of students. Multilingual Education, 6(1), 1-18.

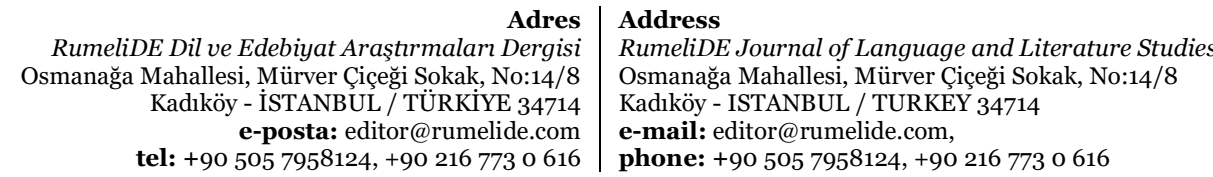


Rukh, S. (2014). Students' attitude towards English language learning and academic achievement: A case of business students in Punjab. European Academic Research, 2(4), 5596-5612.

Sandilos, L. E., Baroody, A. E., Rimm-Kaufman, S. E., \& Merritt, E. G. (2020). English learners' achievement in mathematics and science: Examining the role of self-efficacy. Journal of school psychology, 79, 1-15.

Senemoğlu, N. (2009). Gelişim öğrenme ve öğretim kuramdan uygulamaya. Ankara: PegemA Akademi.

Siregar, M. S., Saragih, A., \& Husein, R. (2018, December). Students Attitudes toward English Conversation Class in the Ways They are. In $3 r d$ Annual International Seminar on Transformative Education and Educational Leadership (AISTEEL 2018) (pp. 704-709). Atlantis Press.

Tran, T. Q., \& Duong, T. M. (2013). The attitudes towards English language learning and use of selfregulated learning strategies among college non-English majors. International Journal of Scientific and Research Publications, 3(7), 1-8.

Wigfield, A., and Wentzel, K. (2007). Introduction to motivation at school: Interventions that work. Educational Psychologist, 42, 191-196.

Yaman, İ. (2018). Türkiye'de İngilizce öğrenmek: zorluklar ve firsatlar. RumeliDE Dil ve Edebiyat Araştırmaları Dergisi, (11), 161-175. 